\title{
Gambaran Faktor Risiko Pasien Stroke Iskemik yang dirawat di Bangsal Saraf RSUD Arifin Achmad Provinsi Riau Periode 1 Januari 2018- 31 Desember 2018
}

\author{
Yossi Maryanti ${ }^{1}$, Devi Susanti ${ }^{2}$, Dhea Maulidyastuti ${ }^{3}$
}

\begin{abstract}
Ischemic stroke is neurological dysfuntion caused by focal cerebral, spinal, or retinal infarction with symptoms persisting for more than 24 hours. Prevalence of ischemic stroke is $87 \%$ of the total stroke. This study aims to describe the risk factors of ischemic stroke patients in neurology ward Arifin Achmad General Hospital Riau province 1 January 201831 December 2018 period. The cross sectional used in this study and the sampling methode was consecutive sampling. There was 150 cases in this study. The result shown that most of ischemic stroke patients at 51-65 year age group $(52,0 \%)$, female $(50,7 \%)$, have optimal total cholesterol levels $(46,7 \%)$, optimal levels of LDL (28,0\%), medium levels of HDL $(55,3 \%)$, optimal levels of trygliceryde $(66,0 \%)$, normal uric acid levels $(63,3)$, have history of hypertension $(60,0 \%)$, have not history of diabetes mellitus $(72,7 \%)$ and history of heart disease $(89,3 \%)$.
\end{abstract}

Keywords : ischemic stroke, neurological dysfuntion, risk factors

Perubahan gaya hidup mengakibatkan peningkatan faktor risiko kejadian penyakit tidak menular seiring dengan perkembangan dunia yang semakin modern, pertumbuhan populasi dan peningkatan usia harapan hidup. Salah satu penyakit tidak menular adalah stroke. ${ }^{1}$ Stroke merupakan gejala klinis dari gangguan fungsi otak fokal atau global yang berkembang dengan cepat dan berlangsung lebih dari 24 jam serta dapat menyebabkan kematian. ${ }^{2}$

Data pada tahun 2011 menunjukkan di dunia insidensi stroke sebanyak 9,0 juta dengan prevalensi 30,7 juta. Insidensi stroke di Asia Tenggara sebanyak 1,8 juta dengan prevalensi 4,5 juta. ${ }^{3}$ Prevalensi stroke di Indonesia berdasarkan Riset Kesehatan Dasar tahun 2018 menunjukkan kenaikan dari 7 per mil tahun 2013 menjadi 10,9 per mil tahun $2018 .{ }^{4}$ Kasus stroke di Rumah Sakit Umum Daerah Arifin Achmad

\footnotetext{
* Korespondensi penulis : dheamldstt@gmail.com

1 KJFD Saraf Fakultas Kedokteran Universitas Riau/ RSUD Arifin Achmad Provinsi Riau

2 KJFD Patologi Klinik Fakultas Kedokteran Universitas Riau/ RSUD Arifin Achmad Provinsi Riau

3 Dhea Maulidyastuti: Mahasiswa Kedokteran Universitas Riau
}

Provinsi Riau pada tahun 2011 sebanyak 264 kasus dan tahun 2012 sebanyak 329 kasus. $^{5}$

Stroke diklasifikasikan menjadi stroke iskemik dan stroke hemoragik. ${ }^{6}$ Kejadian stroke iskemik lebih dominan dengan prevalensi sebanyak $87 \%$ dari total keseluruhan stroke dibanding dengan stroke hemoragik dengan prevalensi perdarahan intraserebral sebanyak $10 \%$ dan perdarahan subarakhnoid sebanyak 3\%.7 Faktor risiko stroke iskemik dibagi menjadi faktor yang tidak dapat dimodifikasi dan faktor risiko yang dapat dimodifikasi. Faktor risiko yang tidak dapat dimodifikasi terdiri dari usia, jenis kelamin, ras dan riwayat penyakit keluarga. Faktor risiko yang dapat dimodifikasi terdiri dari hipertensi, diabetes melitus, penyakit jantung, hiperlipidemia, obesitas dan merokok. ${ }^{8}$

Belum adanya penelitian mengenai gambaran faktor risiko pasien stroke iskemik yang dirawat di bangsal saraf RSUD Arifin Achmad Provinsi Riau mendorong peneliti untuk mengetahui bagaimana gambaran faktor risiko pasien stroke iskemik yang dirawat di bangsal saraf RSUD Arifin Achmad Provinsi Riau. 


\section{METODE}

Jenis penelitian yang digunakan adalah cross sectional. Penelitian ini dilakukan di RSUD Arifin Achmad pada bulan Februari 2019-Mei 2019 di bagian instalasi rekam medis. Populasi pada penelitian adalah seluruh rekam medis pasien yang didiagnosis stroke iskemik di RSUD Arifin Achmad Provinsi Riau periode 1 Januari 2018-31 Desember
2018. Sampel penelitian ini adalah semua pasien yang sesuai dengan populasi yang memenuhi kriteria inklusi dan eksklusi. Teknik pengambilan sampel penelitian ini adalah consecutive sampling. Setelah mendapatkan data yang diperlukan, data tersebut akan dimasukkan pada lembar kerja penelitian. Data disajikan dalam bentuk tabel distribusi frekuensi dengan analisis univariat.

\section{HASIL}

Tabel 1. Distribusi Frekuensi Pasien Stroke Iskemik Berdasarkan Kelompok Usia dan Jenis Kelamin

\begin{tabular}{ccc}
\hline Karakteristik & Frekuensi (n) & Persentase (\%) \\
\hline Kelompok Usia & 2 & 1,3 \\
$\bullet \quad<35$ tahun & 32 & 21,3 \\
$\bullet \quad 35-50$ tahun & 78 & 52,0 \\
$\bullet \quad 51-65$ tahun & 38 & 25,3 \\
$\bullet \quad>65$ tahun & & \\
Jenis Kelamin & 74 & 49,3 \\
$\bullet \quad$ Laki - Laki & 76 & 50,7 \\
$\bullet \quad$ Perempuan & & 100
\end{tabular}

Tabel 1 menunjukkan kelompok usia pasien stroke iskemik paling banyak tergolong kelompok usia 5165 tahun sebesar 52,0\% dengan jenis kelamin laki-laki sebesar 49,3\% (74 kasus).

Tabel 2. Distribusi Frekuensi Pasien Stroke Iskemik Berdasarkan Kadar Kolesterol Total, Kadar LDL, Kadar HDL dan Kadar Trigliserida

\begin{tabular}{|c|c|c|}
\hline Hasil Pemeriksaan & Frekuensi (n) & Persentase (\%) \\
\hline $\begin{array}{cl}\text { Kadar Kolesterol Total } \\
\text { - } & \text { Optimal } \\
\text { - } & \text { Diinginkan } \\
\text { - } & \text { Tinggi }\end{array}$ & $\begin{array}{l}70 \\
41 \\
39\end{array}$ & $\begin{array}{l}46,7 \\
27,3 \\
26,0\end{array}$ \\
\hline $\begin{array}{cl}\text { Kadar LDL } \\
\text { - Optimal } \\
\text { - } \text { Mendekati optimal } \\
\text { - Diinginkan } \\
\text { - Tinggi } \\
\text { - } \\
\text { Sangat Tinggi }\end{array}$ & $\begin{array}{l}42 \\
33 \\
34 \\
26 \\
15\end{array}$ & $\begin{array}{c}28,0 \\
22,0 \\
22,7 \\
17,3 \\
10\end{array}$ \\
\hline $\begin{aligned} & \text { Kadar HDL } \\
& \text { - } \text { Rendah } \\
&- \text { Sedang } \\
& \text { - } \text { Tinggi }\end{aligned}$ & $\begin{array}{l}53 \\
83 \\
14\end{array}$ & $\begin{array}{c}35,3 \\
55,3 \\
9,4\end{array}$ \\
\hline $\begin{array}{cl}\text { Kadar Trigliserida } \\
\text { - } & \text { Optimal } \\
\text { - } & \text { Diinginkan } \\
\text { - } & \text { Tinggi } \\
\text { - } & \text { Sangat Tinggi }\end{array}$ & $\begin{array}{c}99 \\
28 \\
23 \\
0\end{array}$ & $\begin{array}{c}66,0 \\
18,7 \\
15,3 \\
0\end{array}$ \\
\hline Total & 150 & 100 \\
\hline
\end{tabular}


Tabel 3 menunjukkan kadar kolesterol total pasien stroke iskemik paling banyak tergolong kategori optimal sebesar 46,7\% (70 kasus), kadar LDL terbanyak yaitu kategori optimal sebesar $28,0 \%$
(42 kasus), kadar HDL kategori sedang sebesar 55,3\% (83 kasus) dan kadar trigliserida pasien stroke iskemik paling banyak tergolong kategori optimal sebesar $66,0 \%$ (99 kasus).

Tabel 3. Distribusi Frekuensi Pasien Stroke Iskemik Berdasarkan Kadar Asam Urat

\begin{tabular}{ccccccc}
\hline \multirow{2}{*}{ Kadar Asam Urat } & \multicolumn{2}{c}{ Laki-laki } & \multicolumn{2}{c}{ Perempuan } & \multicolumn{2}{c}{ Total } \\
\cline { 2 - 7 } & $\mathrm{n}$ & $\%$ & $\mathrm{n}$ & $\%$ & $\mathrm{n}$ & $\%$ \\
\hline Normal & 50 & 33,3 & 45 & 30,0 & 95 & 63,3 \\
Meningkat & 24 & 16,0 & 31 & 20,7 & 55 & 36,7 \\
\hline Total & 74 & 49,3 & 76 & 50,7 & 150 & 100 \\
\hline
\end{tabular}

Tabel 3 menunjukkan kadar asam urat pasien stroke iskemik paling banyak tergolong kategori normal sebesar 63,3\% (95 kasus).

Tabel 4. Distribusi Frekuensi Pasien Stroke Iskemik Berdasarkan Riwayat Hipertensi, Diabetes Melitus dan Penyakit Jantung

\begin{tabular}{ccc}
\hline Riwayat Penyakit & Frekuensi (n) & Persentase (\%) \\
\hline $\begin{array}{c}\text { Hipertensi } \\
\bullet \quad \text { Ada }\end{array}$ & 90 & \\
$\bullet \quad$ Tidak ada & 60 & 60,0 \\
Diabetes Melitus & & 40,0 \\
$\bullet \quad$ Ada & 41 & \\
$\bullet \quad$ Tidak ada & 109 & 72,7 \\
Penyakit Jantung & & \\
$\bullet \quad$ Ada & 16 & 10,7 \\
$\bullet \quad$ Tidak ada & 134 & 89,3 \\
$\quad$ & \\
\hline
\end{tabular}

Tabel 4 pasien stroke iskemik memiliki riwayat hipertensi sebesar 60,0\% (90 kasus), riwayat diabetes mellitus $27,3 \%$ (41 kasus) dan memiliki riwayat penyakit jantung sebanyak $10,7 \%$ (16 kasus).

\section{PEMBAHASAN}

Pada penelitian ini didapatkan usia yang terbanyak adalah kelompok 51-65 tahun. Adapun usia terendah yang didapatkan yaitu 32 tahun dan usia tertinggi 90 tahun. Hasil penelitian ini menunjukan hasil yang sama dengan penelitian yang dilakukan Kabi (2015) di RSUP Prof. Dr. R. D. Kandou Manado yang menunjukkan bahwa pasien stroke iskemik terbanyak berada pada kelompok usia 51-65 tahun. ${ }^{9}$

Usia merupakan salah satu faktor risiko stroke yang tidak dapat dimodifikasi. Risiko ini meningkat dua kali lipat pada setiap dekade setelah umur 55 tahun dan jarang terjadi pada usia di bawah 35 tahun. ${ }^{10}$ Hal ini disebabkan karena pada saat proses menua advanced glycation end products (AGEs) berakumulasi di berbagai jaringan. Muatan kolagen yang tinggi menyebabkan jaringan ikat menjadi 
kurang elastis dan lebih kaku sehingga mempengaruhi elastisitas pembuluh darah. ${ }^{11}$

Jenis kelamin yang terbanyak menderita stroke pada penelitian ini adlah laki-laki yaitu sebesar 49,3\% (74 kasus). Hal ini serupa dengan penelitian yang Hasibuan (2015) di RSUP Haji Adam Malik yang menunjukkan bahwa pasien stroke iskemik terbanyak merupakan perempuan sebesar 51,0\% (26 kasus). ${ }^{12}$

Jenis kelamin merupakan salah satu faktor risiko stroke yang tidak dapat dimodifikasi.Pria memiliki risiko terkena stroke 1,25 kali dari wanita. Hal ini disebabkan oleh pada usia muda wanita dilindungi dengan hormon estrogen. ${ }^{10}$ Hasil penelitian ini didapatkan sebagian besar perempuan sudah memasuki usia menopause sehingga tidak lagi dilindungi oleh hormon estrogen dan memiliki risiko yang sama dengan laki-laki.

Berdasarkan hasil penelitian didapatkan bahwa pasien stroke iskemik paling banyak memiliki kadar kolesterol total yang tergolong pada kategori optimal yaitu sebesar 46,7\% (70 kasus), lalu diikuti dengan kategori diinginkan sebesar 27,3\% (41 kasus), dan kategori tinggi sebesar 26,0\% (39 kasus). Hasil ini sejalan dengan penelitian yang dilakukan Pratiwi (2017) di RSUD Wates Kulon Progo didapatkan bahwa dari 89 pasien stroke iskemik terdapat 66 pasien stroke iskemik memiliki kadar kolesterol total yang tergolong optimal. ${ }^{13}$

Kolesterol total merupakan total kolesterol dalam darah yang terdiri dari LDL, HDL dan trigliserida. ${ }^{14}$ LDL dapat menstimulasi ekspresi molekul adhesi dan chemoattractants pada permukaan sel endotel yang akhirnya akan menyebabkan aterosklerosis. ${ }^{15}$ HDL menghambat oksidasi LDL, ekspresi molekul adhesi, aktivasi dan agregasi trombosit sehingga dapat mengurangi risiko terjadinya stroke iskemik. ${ }^{16}$ Kadar trigliserida yang tinggi atau hipertrigliseridemia dapat mengubah kaskade koagulasi dan meningkatkan viskositas plasma yang dapat menyebabkan terjadinya trombosis. ${ }^{17}$

Berdasarkan kadar LDL pada penelitian ini tergolong kategori optimal yaitu sebesar 28,0\% (42 kasus) dan yang paling sedikit tergolong kategori sangat tinggi sebesar 10,0\% (15 kasus). Penelitian yang dilakukan oleh Pratiwi (2017) di RSUD Wates
Kulon Progo sejalan dengan penelitian ini dimana didapatkan bahwa dari 89 pasien stroke iskemik terdapat 61 pasien stroke iskemik memiliki kadar LDL yang tergolong optimal. ${ }^{13}$

Low-density lipoprotein (LDL) yang terakumulasi dalam intima akan menstimulasi ekspresi molekul adhesi dan chemoattractants pada permukaan sel endotel yang mengakibatkan monosit bermigrasi ke intima. Monosit akan berdiferensiasi menjadi makrofag dan menginternalisasi serta mengakumulasi kolesterol dalam sel sehingga menjadi sel busa yang merupakan karakteristik dari aterosklerosis. ${ }^{15}$

Pasien stroke iskemik pada penelitian ini paling banyak memiliki kadar HDL yang tergolong pada kategori sedang yaitu sebesar 55,3\% (83 kasus), lalu diikuti dengan kategori rendah sebesar 35,3\% (53 kasus), kategori tinggi sebesar 9,3\% (14 kasus). Penelitian ini sejalan dengan penelitian yang dilakukan Fauzah (2019) di RSAU Salamun Bandung yang menunjukkan bahwa pasien stroke iskemik terbanyak memiliki kadar HDL antara 40-60 mg/ dL. ${ }^{18}$

HDL memliki sifat anti inflamasi dan antioksidan dengan cara menghambat oksidasi LDL, ekspresi molekul adhesi, aktivasi dan agregasi trombosit sehingga dapat mengurangi risiko terjadinya stroke iskemik. Rendahnya kadar HDL yang bersamaan dengan tingginya kadar LDL dan trigliserida dapat meningkatkan risiko terjadinya stroke. ${ }^{16}$

Pasien stroke iskemik didapatkan terbanyak memiliki kadar trigliserida tergolong kategori optimal yaitu sebesar 66,0\% (99 kasus). Penelitian yang dilakukan oleh Pratiwi (2017) di RSUD Wates Kulon Progo sejalan dengan penelitian ini yaitu sebagian besar pasien stroke iskemik memiliki kadar trigliserida yang tergolong optimal yaitu sebesar $77,6 \% .{ }^{13}$ Berdasarkan penelitian yang dilakukan Fauzah (2019) di RSAU Salamun Bandung didapatkan bahwa pasien stroke iskemik terbanyak memiliki kadar trigliserida $\leq 150 \mathrm{mg} / \mathrm{dL} .{ }^{18}$

Trigliserida yang tinggi merupakan salah satu faktor risiko terjadinya stroke. Kadar trigliserida yang tinggi atau hipertrigliseridemia dapat mengubah kaskade koagulasi dan meningkatkan viskositas plasma yang dapat menyebabkan terjadinya trombosis. ${ }^{17}$ 
Pada penelitian ini kadar asam urat yang didapatkan pada pasien stroke iskemik terbanyak pada kategori normal sebesar 63,3\% (95 kasus). Penelitian ini sejalan dengan penelitian yang dilakukan Hasibuan (2015) di RSUP Haji Adam Malik bahwa pasien stroke iskemik terbanyak memiliki kadar asam urat yang normal sebesar $70,6 \%{ }^{12}$

Asam urat dapat berkontribusi dalam aterosklerosis. Peningkatan kadar asam urat dapat meningkatkan oksidasi LDL dan memfasilitasi peroksidasi lipid. Selain itu, peningkatan kadar asam urat berhubungan dengan peningkatan perlekatan trombosit dan lisis trombosit serta proliferasi sel otot polos pembuluh darah. ${ }^{19}$

Sebagian besar pasien stroke iskemik yang dirawat di bangsal saraf RSUD Arifin Achmad Provinsi Riau memiliki riwayat hipertensi yaitu sebesar 60,0\% (90 kasus). Penelitian ini sejalan dengan penelitian yang dilakukan Pajri (2018) di Puskesmas Rejosari Pekanbaru didapatkan bahwa sebanyak $73 \%$ pasien stroke iskemik memiliki riwayat hipertensi. ${ }^{20}$

Hipertensi dapat menyebabkan stroke melalui mikroateroma atau lipohialinosis pada pembuluh darah kecil dan aterosklerosis pada pembuluh darah sedang hingga pembuluh darah besar. ${ }^{21}$ Pembentukan plak aterosklerosis dapat menyebabkan terjadinya oklusi pada pembuluh darah. Selain itu hipertensi dapat menyebabkan hipertrofi dan hiperplasia pada sel otot polos yang dapat menyebabkan penyempitan pada lumen pembuluh darah. ${ }^{22}$ Peningkatan angiotensin II pada keadaan hipertensi dapat merangsang NADPH oksidase untuk menghasilkan ROS. ${ }^{23}$ ROS dapat menyebabkan proliferasi pada sel otot polos. ${ }^{22}$

Pasien stroke iskemik yang dirawat di bangsal RSUD Arifin Achmad Provinsi Riau yang memiliki riwayat diabetes melitus sebesar 27,3\% (41 kasus). Hasil penelitian ini serupa dengan penelitian yang dilakukan Kabi (2015) di RSUP Prof. Dr. R. D. Kandou Manado yang menunjukkan 73,4\% dari pasien stroke iskemik tidak memiliki riwayat penyakit diabetes melitus. ${ }^{9}$

Keadaan hiperglikemia pada pasien diabetes dapat meningkatkan reactive oxygen species (ROS). Peningkatan ROS dapat menyebabkan disfungsi endotel dengan cara inaktivasi endothelial nitric oxide synthase (eNOS) dan penurunan kadar nitic oxide (NO). Selain itu, ROS dapat menginduksi ekspresi molekul adhesi yang memfasilitasi perekrutan sel inflamasi dan deposisi lemak di sel intimal. Makrofag dan monosit akan mengingesti kelebihan LDL yang teroksidasi dan menghasilkan sitokin inflamasi dan growth factors yang menyebabkan proliferasi dari sel otot polos pembuluh darah sehingga terjadi aterosklerosis. ${ }^{24}$

Pasien stroke iskemik yang dirawat di bangsal RSUD Arifin Achmad Provinsi Riau memiliki riwayat penyakit jantung sebesar 10,7\% (16 kasus). Hasil penelitian ini sejalan dengan penelitian yang dilakukan Kabi (2015) di RSUP Prof. Dr. R. D. Kandou Manado yang menunjukkan $87 \%$ dari pasien stroke iskemik tidak memiliki riwayat penyakit jantung. ${ }^{9}$

Penyakit jantung koroner, kardiomiopati, gagal jantung dan fibrilasi atrium dapat menyebabkan pembekuan darah yang akan menyebabkan terjadinya stroke. Fibrilasi atrium dapat menyebabkan stroke iskemik dikarenakan pada fibrilasi atrium jantung berkontraksi lebih cepat dan tidak teratur sehingga terjadi penumpukan darah di ruang jantung yang akan meningkatkan risiko terjadinya bekuan darah. $^{25}$

\section{SIMPULAN}

Pasien stroke iskemik terbanyak di Instalasi Rekam Medik RSUD Arifin Achmad Provinsi terbanyak berada pada kelompok usia 51-65 tahun $(52,0 \%)$, berjenis kelamin perempuan $(50,7 \%)$, memiliki kadar kolesterol total yang optimal $(46,7 \%)$, kadar LDL yang optimal (28,0\%), kadar HDL yang tergolong kategori sedang $(55,3 \%)$, kadar trigliserida yang optimal $(66,0 \%)$, kadar asam urat yang normal $(63,3 \%)$, memiliki riwayat hipertensi $(60,0 \%)$, tidak memiliki riwayat diabetes melitus $(72,7 \%)$ dan tidak memiliki riwayat penyakit jantung $(89,3 \%)$.

\section{DAFTAR PUSTAKA}

1. Kementrian Kesehatan RI. Penyakit tidak menular. Buletin jendela data dan informasi kesehatan. 2012 dapat diunduh di http:// $\underline{w} \mathrm{w}$ w. $\mathrm{d}$ e $\mathrm{p} \mathrm{k}$ e $\mathrm{s} \cdot \mathrm{g} 0 \cdot \mathrm{i} \mathrm{d} /$ 
download.php?file=download/pusdatin/buletin/ buletin-ptm.pdf.

2. Sacco RL, Kasner SE, Broderick JP, Caplan LR, Connors JJ, Culebras A, et al. An updated definition of stroke for the 21 st century: A statement for healthcare professionals from the American heart association/American stroke association. Stroke. 2013;44(7):2064-89.

3. Fisher M, Norrving B. International agenda for stroke. Int Agenda stroke. 2011;4.

4. Badan Penelitian dan Pengembangan Kesehatan Departemen Kesehatan. Riset Kesehatan Dasar. 2018 dapat diunduh dihttp://www.depkes.go.id/ resources/download/info-terkini/ $\underline{\mathrm{materi}} \mathrm{rak}$ orpop $2018 /$ Hasil\%20Riskesdas\%202018.pdf

5. Irdelia RR. Profil faktor risiko yang dapat dimodifikasi pada kasus stroke berulang di RSUD Arifin Achmad Provinsi Riau [skripsi]. Pekanbaru: Universitas Riau; 2014.

6. Parmar P, Sumaria S, Hashi S. Stroke: Classification and diagnosis. Clin Pharm. 2011;3(7):200-2.

7. Go AS, Mozaffarian D, Roger VL, Benjamin EJ, Berry JD, Borden WB, et al. Heart Disease and Stroke Statistics - 2013 Update: A Report From the American Heart Association. Circulation. 2013; 127:e6-e245.

8. Choudhury JH, Chowdhury TI, Nayeem A, Jahan WA. Modifiable and non-modifiable risk factors of stroke/ : A review update. J Natl Inst Neurosci Bangladesh. 2015;1(1):22-6.

9. Kabi GYCR, Tumewah R, Kembuan MAHN. Gambaran faktor risiko pada penderita stroke iskemik yang dirawat inap neurologi RSUP Prof. Dr . R . D . Kandou Manado periode Juli 2012Juni 2013.Jurnal e-Clinic. 2015;3(1):457-62.

10. Polikandrioti M. Non-modifiable risk factors for ischemic stroke. HSJ. 2009;1:1-2.

11. Setiati S, Harimurti K, Govinda A. Proses menua dan implikasi klinisnya. In: Setiati S, Alwi I, Sudoyo AW, Simadibrata K M, Setiyohadi B, Fahrial Syam A, editors. Buku AjarIlmu Penyakit Dalam edisi VI. Jakarta: Internal Publishing; 2014. p. 3673.
12. Hasibuan MAF. Peran low density lipoprotein dan asam urat sebagai faktor independen terhadap stroke iskemik di Rumah Sakit Umum Pusat H. Adam Malik [skripsi]. Medan: Universitas Sumatera Utara; 2015.

13. Pratiwi N. Hubungan antara lipid dengan kejadian stroke tahun 2016 di RSUD Wates Kulon Progo [skripsi]. Yogyakarta: Sekolah Tinggi Ilmu Kesehatan Jendral Achmad Yani; 2017.

14. My.clevelandclinic.org [homepage on internet]. Ohio: Cleveland Clinic Institutes. [updated 2017 July 27; citied 2019 May 1]. Available from: https:/ /my.clevelandclinic.org/health/articles/11920cholesterol-numbers-what-do-they-mean.

15.Zhang B, Gao C, Yang N, Zhang W, Song X, Yin $\mathrm{J}$, et al. Is elevated SUA associated with a worse outcome in young chinese patients with acute cerebral ischemic stroke/ ?. BMC Neurol. 2010 Sep:1-6.

16. Habibi-koolaee M, Shahmoradi L, Kalhori SRN, Ghannadan H, Hosseini A, Younesi E. Lipid profile and the risk of stroke/ : A study from North of Iran. J Res Med Dent Sci. 2018;6(1):343-49.

17.Lisak M, Demarin V, Trkanjec Z, Bašiæ-kes V. Hypertriglyceridemia as a possible independent risk factor for stroke. Acta Clin Croat. 2013;52(4):458-63.

18. Fauzah U, Nurimaba N, Tursina A. Gambaran profil lipid pasien stroke iskemik dan stroke perdarahan usia muda di RSAU Salamun Bandung. Prosiding Pendidikan Dokter. 2019;5(1):586-94.

19. Seet RCS, Kasiman K, Gruber J, Tang S, Wong $\mathrm{M}$, Chang $\mathrm{H}$, et al. Is uric acid protective or deleterious in acute ischemic stroke/ ? A prospective cohort study. Atherosclerosis. 2010;209(1):215-9.

20.Pajri RN, Safri, Dewi YI. Gambaran faktor-faktor penyebab terjadinya stroke. Jurnal Online Mahasiswa. 2018;5(1):436-43.

21.Hisham NF, Bayraktutan U. Epidemiology, pathophysiology, and treatment of hypertension in ischaemic stroke patients. J Stroke Cerebrovasc Dis. 2013;22(7):e4-14. 
22. Yu J, Zhou R, Cai G. From hypertension to stroke/ : mechanisms and potential prevention strategies. CNS Neuroscience \& Theurapeutics. 2011;17(5):577-84.

23.Rajendran P, Rengarajan T, Thangavel J, Nishigaki Y, Sakthisekaran D, Sethi G, et.al. The vascular endothelium and human diseases. Int. J. Biol. Sci. 2013;9(10):1057-69.
24. Kaneto H, Katakami N, Matsuhisa M, Matsuoka $\mathrm{T}$. Role of reactive oxygen species in the progression of type 2 diabetes and atherosclerosis. 2009 Nov:1-11

25. Nhlbi.nih.gov [homepage on internet] Bethesda: National heart, lung and blood. [updated 2018 April 14; citied 2019 January 2019]. Available from: https://www.nhlbi.nih.gov/health-topics/ stroke 